\title{
Strenuous endurance exercise: is more better for everyone? Our genes won't tell us
}

\author{
André La Gerche, ${ }^{1,2}$ David L Prior, ${ }^{1}$ Hein Heidbüchel'
}

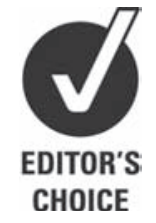

If we could give every individual the right amount of nourishment and exercise, not too little and not too much, we would have found the safest way to health.-Hippocrates circa $400 \mathrm{BC}$

As eloquently described by our colleagues Ruiz et al, ${ }^{1}$ numerous large observational and cohort studies have provided compelling evidence for the benefit of mild and moderate exercise on cardiovascular health and mortality. That the benefit of exercise intensity and duration continues to increase into the realms of intense competitive sport is more controversial. This is of importance given that endurance sporting events continue to increase in popularity. For example, over one million Americans competed in an endurance triathlon last year, and participation rates are currently increasing by $10-20 \%$ per annum. ${ }^{2}$ The last half-century has seen an increase in morbidity associated with a lack of habitual exercise and a simultaneous increase in the number of people performing exercise well in excess of recommendations. Very appropriately, the public health focus has been on addressing inactivity, but it may be presumptive to assume that there is no upper limit to what constitutes healthy exercise for the heart. There is accumulating evidence that strenuous endurance exercise may be associated with an increase in some cardiac arrhythmias and speculation that some of the structural changes associated with the 'athlete's heart' may not always be benign. Thus, there is a clear need to expand our understanding of the effects of greater doses of exercise.

\section{A PROBLEM WITH DEFINITIONS}

The non-standardised gradations of exercise intensity complicate interpretation

\section{'Department of Cardiology, St Vincent's Hospital, University of Melbourne, Melbourne, Australia ${ }^{2}$ Department of Cardiovascular Medicine, University Hospital, University of Leuven, Leuven, Belgium}

Correspondence to André La Gerche, Department of Cardiology, St Vincent's Hospital, P.O. Box 2900, Fitzroy 3065, Australia; andre.lagerche@svhm.org.au of exercise studies. There is compelling evidence that 'strenuous exercise' is associated with improved cardiovascular outcomes, but it must be noted that the definition of 'strenuous' is derived from middle-aged non-athletic populations. For example, Blair et a $\beta$ ascribed a delay in allcause mortality to 'high levels of fitness', but estimated the 'asymptote of benefit' to be approximately 9 metabolic equivalents (METS) in women and 10 METS in men, beyond which further benefits may not be expected. This approximates to slow running or an oxygen consumption of $35 \mathrm{ml} / \mathrm{kg} / \mathrm{min}$, an intensity at which most well-trained athletes would be at only $50 \%$ of their capacity. There is little overlap between the ranges of exercise for which we attribute cardiovascular benefit and those which are routinely practised by athletes. Perhaps more importantly, the maximal exercise levels for which we have good evidence of benefit are below that expected for exercise-induced cardiac remodelling, the so-called 'athlete's heart' to occur. We should not assume that the benefit from lower intensities can be generalised to the high-level training which induces changes in cardiac morphology.

\section{BEING A COMPETITIVE ENDURANCE ATHLETE IS HEALTHY, BUT IS THAT A RESULT OF STRENUOUS EXERCISE?}

While most large cohort studies have failed to include doses of exercise relevant to that practised by competitive endurance athletes, some reassurance about higher doses of exercise has been provided by the description of excellent health outcomes in 2613 elite Finnish athletes who competed between 1920 and 1965. ${ }^{4}$ As compared with age-matched referents chosen from records of induction into compulsory military service, the 303 endurance athletes had longer life expectancy $(75.6$ vs 69.9 years, $p<0.01$ for analysis of survival curves). However, it is clear that the populations differ in many respects other than their athletic status alone. Athletes were more than twice as frequently nonsmokers, consumed less alcohol, experienced less weight gain and were more frequently in higher occupational strata. These differences are reflected in the causespecific mortality for this cohort in which the greatest relative reductions were in obstructive airways disease and lung cancer. ${ }^{5}$ Thus, while it seems clear that being an athlete is healthy, these studies do not enable analysis as to whether mortality benefits are due to lifestyle factors, exercise or a combination of both. The ideal study to assess the impact of strenuous endurance exercise on health outcomes would compare cohorts of matched cardiovascular risk profiles but differing exercise regimes. While no such study exists, some inference may be gained from two studies in which mortality was compared according to athletic proficiency-perhaps a reasonable surrogate for exercise dose. Farahmand et al described a reduction in expected mortality among competitive skiers in Sweden, but found no difference between the least and most trained athletes. van Saase et al assessed mortality in 2259 participants in the 32 years following a $200 \mathrm{~km}$ Dutch skating tour and found that those athletes finishing within $2 \mathrm{~h}$ of the winner had a similar life expectancy to the general population while recreational participants had higher than expected life expectancy. Thus, a greater benefit could not be established for strenuous endurance exercise when compared with more moderate exercise practise.

\section{POTENTIAL CARDIAC MORBIDITY AMONG COMPETITIVE ENDURANCE ATHLETES}

Speculation that habitual intense endurance exercise may be associated with cardiac pathology in some individuals is based on three lines of circumstantial evidence: permanent changes in cardiac structure, an increase in cardiac arrhythmias and functional impairment following prolonged intense exercise.

\section{Athlete's heart: physiology versus pathology?}

Morphology of the athlete's heart is relatively well defined. There is enlargement of all cardiac chambers, which is greatest in those practising sports that combine endurance and power. ${ }^{8}$ The chamber dilation enables greater cardiac output and $\mathrm{Vo}_{2}$ max during exercise $e^{9}$ while increases in ventricular wall thickness redress the increases in wall stress incurred as a result of larger chambers. Thus, the changes that are observed are in keeping with a proportional response to the physiological load. However, there are some suggestions that in addition to myocyte hypertrophy, 
athletic heart remodelling results in expansion of the extracellular matrix resulting in permanent structural changes which may portend an increased risk of arrhythmias. Studies of elite athletes have demonstrated that ventricular dilation progresses with continued training ${ }^{10}$ and may not completely regress with de-training, even after many years. ${ }^{11}$ Electrophysiological changes may also reflect an element of permanent remodelling. Stein et a ${ }^{12}$ used double pharmacological blockade to demonstrate that reductions in sinus and atrioventricular node automaticity were in part due to intrinsic tissue changes rather than being entirely attributable to upregulation of the autonomic nervous system. This mechano-electrical remodelling may have long-term consequences as demonstrated by the excess sinus node disease diagnosed in the chronically enlarged hearts of retired professional cyclists. ${ }^{13} 14$ Histological evidence of fibrosis in athletes' hearts has also been reported, ${ }^{15-18}$ but should be interpreted with caution given that it is based entirely on case observations taken from athletes with cardiac symptoms or other co-morbidities. Other non-invasive surrogate measures of fibrosis such as delayed enhancement on cardiac magnetic resonance studies $^{19} 20$ and biochemical markers ${ }^{21}$ have also stimulated debate regarding whether the remodelling associated with athlete's heart is always benign. This remains a critical unanswered question. ${ }^{22}$

\section{Increased arrhythmias?}

There is increasing evidence that strenuous endurance exercise is associated with an increased prevalence of atrial fibrillation (AF). Even within ranges of exercise below those practised by athletes, a U-shaped exercise response curve has been described whereby mild exercise is associated with a lower incidence of AF while the risk increases with more 'vigorous' exercise. ${ }^{23} 24$ At 'extremely vigorous' exercise doses, numerous case-control and observational studies provide evidence that endurance athletes experience higher rates of AF than non-athletes. ${ }^{25}$ Athlete's heart has also been associated with an increase in ventricular ectopy and/or ventricular tachycardia. ${ }^{13}$ 26-29 Biffi et al demonstrated that, in the absence of structural cardiac abnormalities, ventricular arrhythmias largely resolved with de-training and were not associated with clinical events during long-term followup. ${ }^{17} 2627$ Heidbüchel et al, on the other hand, described an alarming rate of serious arrhythmic sequelae and sudden death among a cohort of elite endurance athletes who had presented with complex ventricular arrhythmias. ${ }^{29}$ This was associated with structural right ventricular abnormalities while left ventricular abnormalities were uncommon. Right ventricular ejection fraction was lower among athletes with ventricular arrhythmias than in asymptomatic athletes, ${ }^{28}$ and affected athletes had a lower rate of genetic mutations than would be expected if these findings were attributable to an underlying familial disease. ${ }^{17}$ We have contended that extreme endurance exercise may exact a disproportionate ventricular strain resulting in proarrhythmogenic remodelling of the right ventricle and that future studies assessing the significance of athlete's heart must include assessment of this chamber.

\section{Post-race cardiac impairment}

Multiple studies have detailed increases in cardiac troponin and natriuretic peptides and left ventricular abnormalities following intense prolonged exercise. ${ }^{30} 31$ The term cardiac 'fatigue' has often been favoured to reflect prompt and complete cardiac recovery. However, whereas evidence of left ventricular impairment has been inconsistent and usually mild, right ventricular function is more frequently and more profoundly affected. ${ }^{32-36}$ Moderate right ventricular dysfunction has been demonstrated using echocardiography ${ }^{32}$ and $\mathrm{MRI}^{35} 36$ even in the absence of any apparent left ventricular abnormalities. The reason for this preponderance of right ventricular impairment is uncertain, but it raises important questions as to whether repeated insults could explain the chronic right ventricular injury and arrhythmias described in elite endurance athletes. ${ }^{29}$

\section{UNFAMILIAR GENETIC TERRITORY}

Ruiz and colleagues argue that the increasingly sedentary modern western lifestyle is at odds with a genome which has been programmed through millenniums of obligatory daily activity. However, it must also be noted that there is no historical precedent for the levels of sustained exertion demanded by modern endurance sport. Thus, it may be argued, the human heart is programmed for moderate exercise whereas the divergent trends of the last 50 years-inactivity and extreme endurance sporting events-are unfamiliar territory.

Many centuries on, Hippocrates' counsel cautioning 'too little' exercise has proven wise, we should now more carefully appraise how much is 'too much'.

\section{Competing interests None}

Provenance and peer review Not commissioned; not externally peer reviewed

Accepted 28 October 2010

Published Online First 27 December 2010

Br J Sports Med 2011;45:162-164.

doi:10.1136/bjsm.2010.081141

\section{REFERENCES}

1. Ruiz JR, Morán M, Arenas J, et al. Strenuous endurance exercise improves life expectancy: it's in our genes. Br J Sports Med Published Online First: 27 September 2010. doi:10.1136/bjsm.2010.075085.

2. USA Triathlon. Triathlon Participation, Growth Trends and Demographics, 2009. http://www.usatriathlon. org/about-usat/demographics (accessed August 2010).

3. Blair SN, Kohl HW, 3rd, Paffenbarger RS, Jr, et al. Physical fitness and all-cause mortality. A prospective study of healthy men and women. JAMA 1989;262:2395-401.

4. Sarna S, Sahi T, Koskenvuo M, et al. Increased life expectancy of world class male athletes. Med Sci Sports Exerc 1993;25:237-44.

5. Kujala UM, Tikkanen HO, Sarna S, et al. Diseasespecific mortality among elite athletes. JAMA 2001;285:44-5.

6. Farahmand BY, Ahlbom A, Ekblom 0, et al. Mortality amongst participants in Vasaloppet: a classical long-distance ski race in Sweden. J Intern Med 2003;253:276-83.

7. van Saase JL, Noteboom WM, Vandenbroucke JP. Longevity of men capable of prolonged vigorous physical exercise: a 32 year follow up of 2259 participants in the Dutch eleven cities ice skating tour. BMJ 1990;301:1409-11.

8. Pluim BM, Zwinderman AH, van der Laarse A, et al. The athlete's heart. A meta-analysis of cardiac structure and function. Circulation 2000;101:336-44.

9. Steding K, Engblom H, Buhre T, et al. Relation between cardiac dimensions and peak oxygen uptake. J Cardiovasc Magn Reson 2010;12:8.

10. Abergel E, Chatellier G, Hagege AA, et al. Serial left ventricular adaptations in world-class professional cyclists: implications for disease screening and follow-up. J Am Coll Cardiol 2004;44:144-9.

11. Pelliccia A, Maron BJ, De Luca R, et al. Remodeling of left ventricular hypertrophy in elite athletes after long-term deconditioning. Circulation 2002;105:944-9.

12. Stein R, Medeiros CM, Rosito GA, et al. Intrinsic sinus and atrioventricular node electrophysiologic adaptations in endurance athletes. J Am Coll Cardiol 2002;39:1033-8.

13. Baldesberger $\mathbf{S}$, Bauersfeld U, Candinas R, et al Sinus node disease and arrhythmias in the long-term follow-up of former professional cyclists. Eur Heart J 2008;29:71-8.

14. Luthi $\mathbf{P}$, Zuber M, Ritter M, et al. Echocardiographic findings in former professional cyclists after long-term deconditioning of more than 30 years. Eur J Echocardiogr 2008;9:261-7.

15. Zeppilli P, Santini C, Palmieri V, et al. Role of myocarditis in athletes with minor arrhythmias and/or echocardiographic abnormalities. Chest 1994;106:373-80.

16. Whyte G, Sheppard M, George K, et al. Post-mortem evidence of idiopathic left ventricular hypertrophy and idiopathic interstitial myocardial fibrosis: is exercise the cause? Br J Sports Med 2008;42:304-5.

17. La Gerche A, Robberecht C, Kuiperi $C$, et al. Lower than expected desmosomal gene mutation prevalence in endurance athletes with complex ventricular arrhythmias of right ventricular origin. Heart 2010;96:1268-74. 
18. Harper RW, Mottram PM. Exercise-induced right ventricular dysplasia/cardiomyopathy-an emerging condition distinct from arrhythmogenic right ventricular dysplasia/cardiomyopathy. Heart Lung Circ 2009;18:233-5.

19. Breuckmann F, Möhlenkamp S, Nassenstein K, et al. Myocardial late gadolinium enhancement: prevalence, pattern, and prognostic relevance in marathon runners. Radiology 2009;251:50-7.

20. Möhlenkamp S, Lehmann N, Breuckmann F, et al. Running: the risk of coronary events: Prevalence and prognostic relevance of coronary atherosclerosis in marathon runners. Eur Heart J 2008;29:1903-10.

21. Lindsay MM, Dunn FG. Biochemical evidence of myocardial fibrosis in veteran endurance athletes. Br J Sports Med 2007;41:447-52.

22. La Gerche A, Taylor AJ, Prior DL. Athlete's heart: the potential for multimodality imaging to address the critical remaining questions. JACC CardiovasC Imaging 2009;2:350-63.

23. Mozaffarian D, Furberg CD, Psaty BM, et al. Physical activity and incidence of atrial fibrillation in older adults: the cardiovascular health study. Circulation 2008;118:800-7.
24. Aizer A, Gaziano JM, Cook NR, et al. Relation of vigorous exercise to risk of atrial fibrillation. $\mathrm{Am} \mathrm{J}$ Cardiol 2009;103:1572-7.

25. Mont L, Elosua R, Brugada J. Endurance sport practice as a risk factor for atrial fibrillation and atrial flutter. Europace 2009;11:11-17.

26. Biffi A, Pelliccia A, Verdile L, et al. Long-term clinical significance of frequent and complex ventricular tachyarrhythmias in trained athletes. J Am Coll Cardiol 2002;40:446-52

27. Biffi A, Maron BJ, Verdile L, et al. Impact of physical deconditioning on ventricular tachyarrhythmias in trained athletes. J Am Coll Cardiol 2004;44:1053-8.

28. Ector J, Ganame J, van der Merwe N, et al. Reduced right ventricular ejection fraction in endurance athletes presenting with ventricular arrhythmias: a quantitative angiographic assessment. Eur Heart J 2007;28:345-53.

29. Heidbüchel H, Hoogsteen J, Fagard R, et al. High prevalence of right ventricular involvement in endurance athletes with ventricular arrhythmias. Role of an electrophysiologic study in risk stratification. Eur Heart J 2003;24:1473-80.
30. Scharhag J, George K, Shave R, et al. Exerciseassociated increases in cardiac biomarkers. Med Sci Sports Exerc 2008;40:1408-15.

31. Whyte GP. Clinical significance of cardiac damage and changes in function after exercise.

Med Sci Sports Exerc 2008;40:1416-23.

32. La Gerche A, Connelly KA, Mooney DJ, et al. Biochemical and functional abnormalities of left and right ventricular function after ultra-endurance exercise. Heart 2008;94:860-6.

33. Neilan TG, Januzzi JL, Lee-Lewandrowski E, et al. Myocardial injury and ventricular dysfunction related to training levels among nonelite participants in the Boston marathon. Circulation 2006;114:2325-33.

34. Neilan TG, Yoerger DM, Douglas PS, et al. Persistent and reversible cardiac dysfunction among amateur marathon runners. Eur Heart J 2006;27:1079-84.

35. Mousavi N, Czarnecki A, Kumar K, et al. Relation of biomarkers and cardiac magnetic resonance imaging after marathon running. Am J Cardiol 2009;103:1467-72.

36. Trivax JE, Franklin BA, Goldstein JA, et al. Acute cardiac effects of marathon running. J Appl Physiol 2010;108:1148-53. 